
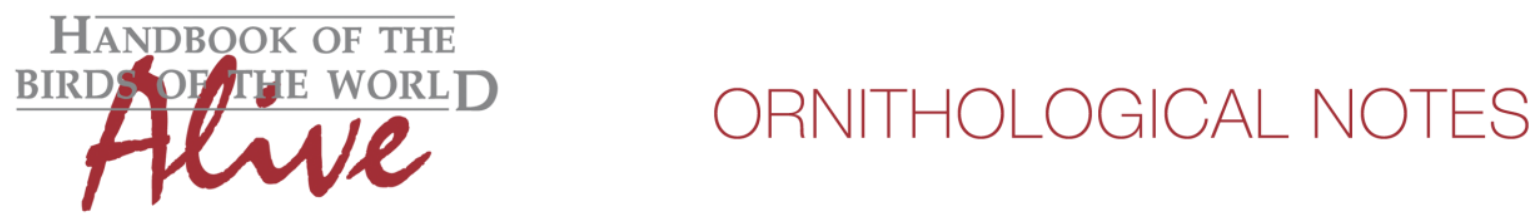

\title{
Notes on the vocalizations of Plumbeous Vireo (Vireo plumbeus)
}

Peter Boesman

In the following we briefly analyze and compare voice of the different races of Plumbeous Vireo (Vireo plumbeus). We also try to quantify the extent of any vocal differences using the criteria proposed by Tobias et al. (2010), as a support for taxonomic review. We have made use of sound recordings available on-line from Xeno Canto (XC) and Macaulay Library (ML).

Primary song of all races is a variable short phrase of one or two complex notes given at intervals of about 2 seconds. Race montanus seems to have song phrases which are often simpler and purer, with less modulations and less harmonics in the notes, and with hardly burry quality to the notes. Typical phrases can be identified, but there is some overlap in which case it is difficult to decide to which group the recording belongs.

Some typical phrases:

Honduras

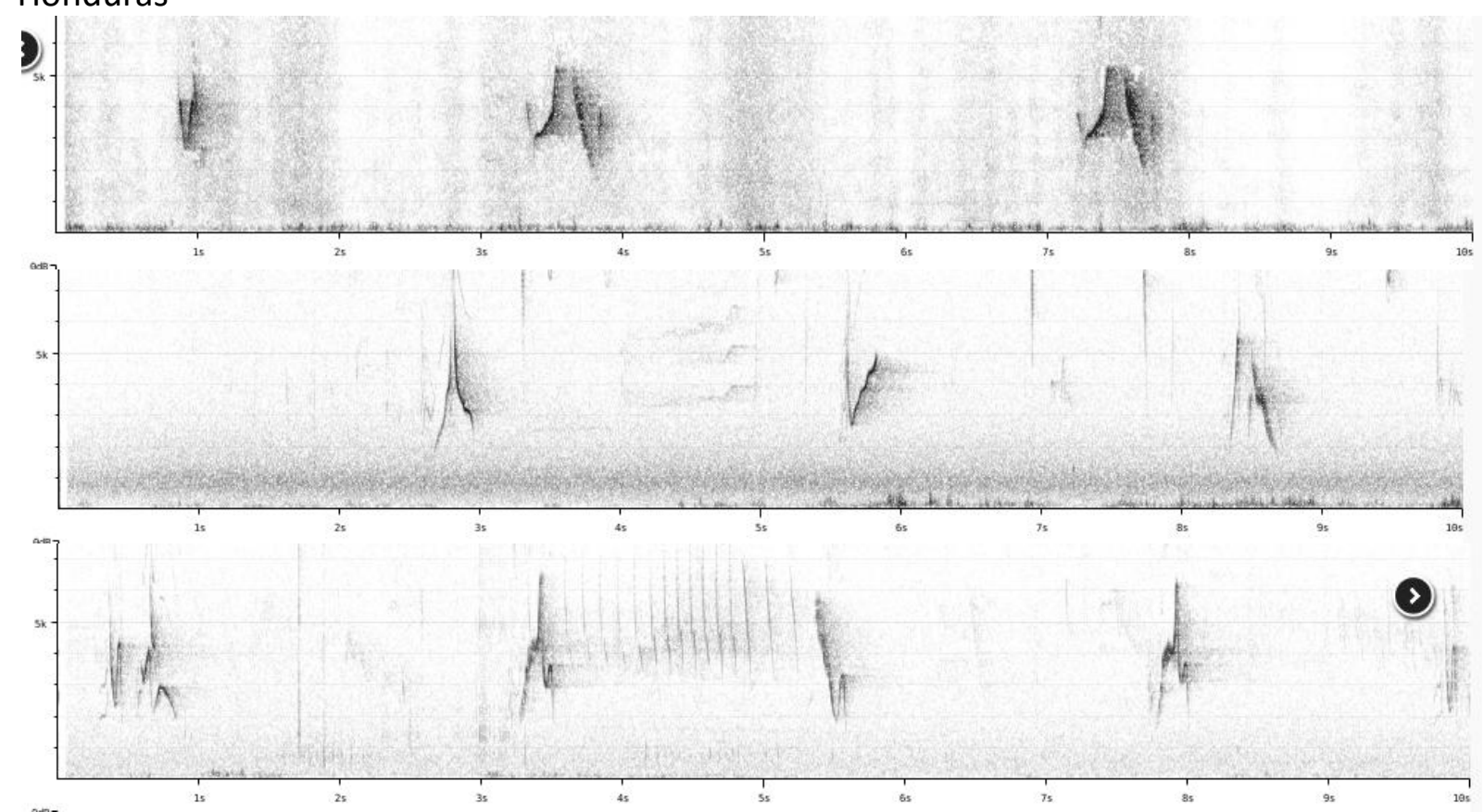

(last example is closest to northern races)

Nicaragua (June, seemingly a range extension)

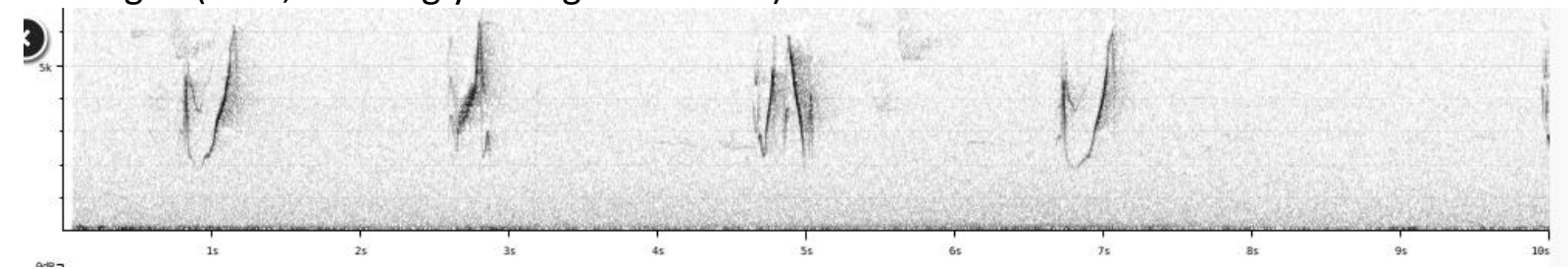




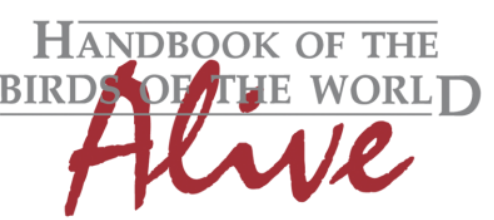

\section{ORNITHOLOGICAL NOTES}

There is 1 recording from Belize (April), presumably of race notius:

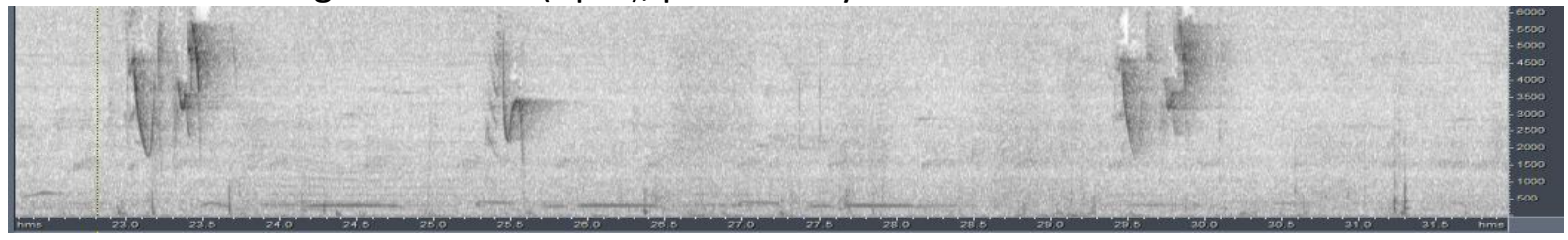

to be compared with some typical phrases of populations $\mathrm{N}$ of the Isthmus:
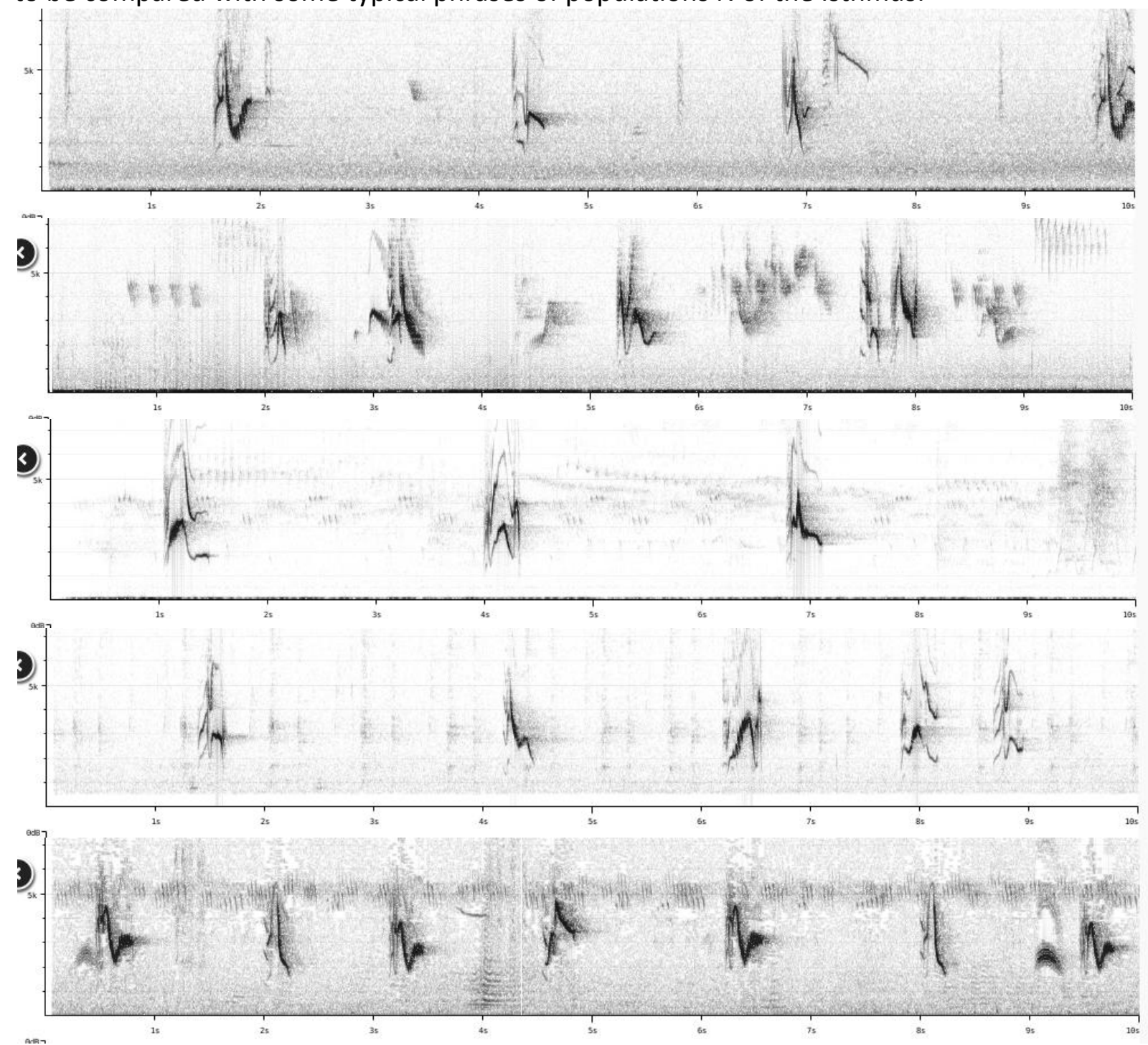
While differences are quite clear by ear and on sonograms, scoring based on quantifiable parameters is less straightforward. One could e.g. measure amplitude of harmonics, $\%$ of burry notes in song phrases etc., which would then lead to a vocal score of about $1+1=2$ for race montanus vs. northern populations of $V$. plumbeus.

The single recording of presumed notius is rather like montanus, but this obviously needs further confirmation when more recordings become available.

This note was finalized on 20th October 2015, using sound recordings available on-line at that moment. We would like to thank in particular the many sound recordists who placed their recordings for this species.

\section{References}

Tobias, J.A., Seddon, N., Spottiswoode, C.N., Pilgrim, J.D., Fishpool, L.D.C. \& Collar, N.J. (2010). Quantitative criteria for species delimitation. Ibis 152(4): 724-746.

\section{Recommended citation}

Boesman, P. (2016). Notes on the vocalizations of Plumbeous Vireo (Vireo plumbeus). HBW Alive Ornithological Note 170. In: Handbook of the Birds of the World Alive. Lynx Edicions, Barcelona. (retrieved from http://www.hbw.com/node/932100 on 19 August 2016). 